\title{
The Wave Climate of the Southern Ocean
}

\author{
Ian R. Young, Emmanuel Fontaine, QingXiang LiU, and AleXAnder V. BABAnin \\ Department of Infrastructure Engineering, University of Melbourne, Melbourne, Victoria, Australia
}

(Manuscript received 31 January 2020, in final form 12 March 2020)

\begin{abstract}
The wave climate of the Southern Ocean is investigated using a combined dataset from 33 years of altimeter data, in situ buoy measurements at five locations, and numerical wave model hindcasts. The analysis defines the seasonal variation in wind speed and significant wave height, as well as wind speed and significant wave height for a 1-in-100-year return period. The buoy data include an individual wave with a trough to crest height of $26.4 \mathrm{~m}$ and suggest that waves in excess of $30 \mathrm{~m}$ would occur in the region. The extremely long fetches, persistent westerly winds, and procession of low pressure systems that traverse the region generate wave spectra that are unique. These spectra are unimodal but with peak frequencies that propagate much faster than the local wind. This situation results in a unique energy balance in which waves at the spectra peak grow as a result of nonlinear transfer without any input from the local wind.
\end{abstract}

\section{Introduction}

The Southern Ocean is often defined as the region south of $60^{\circ} \mathrm{S}$. However, from the point of view of wave climate, this is not a useful definition. Rather, it is more useful to define the Southern Ocean as the region south of the main landmasses of Africa, Australia, and South America and north of the Antarctic ice edge. That is, the region between latitudes of approximately $40^{\circ}$ and $60^{\circ} \mathrm{S}$. This is an area of ocean of approximately $50 \times 10^{6} \mathrm{~km}^{2}$. As seen in Fig. 11, the extent of the winter ice edge does not actually conform to a single latitude. Rather, it extends north to approximately $55^{\circ} \mathrm{S}$ in the region between South America and Africa (Atlantic sector) and to $65^{\circ} \mathrm{S}$ in the regions between Africa and Australia (Indian Ocean sector) and between Australia and South America (Pacific sector). This body of water is unique globally, as its circles the globe, interrupted only by the approximately $1000-\mathrm{km}$-wide constriction provided by Drake Passage between the tip of South America and the Antarctic Peninsula. The climatology of the region is such that the strongest westerly winds on Earth blow across the Southern Ocean with a procession of low pressure systems propagating west to east around Antarctica.

The remoteness of much of the Southern Ocean means that measurements of the wave climate of the region are very limited. For centuries, ship observations

Corresponding author: Ian R. Young, ian.young@unimelb.edu.au clearly recognized this was an area with sustained high sea states, but the first observations confirming the magnitude of the wave climate were not obtained until the advent of the limited Seasat altimeter mission (Mognard et al. 1983, 1986). The importance of the region as a major generation source for swell that is ubiquitous across the Indian, Pacific, and South Atlantic Oceans has also become clear following model and satellite studies (Young 1994a, 1999; Semedo et al. 2011; Alves 2006). More recently, it has become clear that this is also a region where the wave (and wind) climate has been changing and is projected to change in the future (Young et al. 2011; Young and Ribal 2019; Morim et al. 2019; Meucci et al. 2018).

The Southern Ocean is also a unique wind-wave generation environment. There is no other region of the world where such long (almost infinite) fetches exist and hence the region represents a unique test of our understanding of the physics of wind-wave generation and evolution. This huge body of water also stores more anthropogenic heat and carbon dioxide than any other latitude band on Earth. The Antarctic Circumpolar Current, the world's largest ocean current, merges the waters of the Atlantic, Indian, and Pacific Oceans and carries up to 150 times the volume of the world's rivers combined.

Despite the global importance of the region, available data on the wave climate of the region are still very limited. This paper brings together a range of data 
sources to provide an overview of the wave climate and the physical processes active in generating this Southern Ocean wave climate. These data sources consist of 33 years of satellite altimeter data, in situ buoy observations from five sites across the Southern Ocean, and numerical model hindcast results.

The structure of this paper is as follows. Section 2 provides an overview of previous observations of Southern Ocean wave climate. This is followed by a description of the data sources used for this study in section 3. The seasonal variation in mean and upper percentile wind and wave conditions is provided in section 4 , and a description of extreme conditions is given in section 5. Section 6 provides a detailed description of wave spectra recorded at in situ buoy sites across the region followed in section 7 by a detailed investigation of the physical processes responsible for the observed spectra.

\section{Southern Ocean wave observations}

The earliest observations of the wave climate of the Southern Ocean were obtained from the very limited (August and September 1978) altimeter data provided by the Seasat mission (Mognard et al. 1983, 1986). This was later expanded with the launch of Geosat (1985-88) (Young 1994a; Josberger and Mognard 1996). These studies provided the first observations of mean monthly significant wave height $H_{s}$ across the region and confirmed mean monthly values during winter in excess of $5 \mathrm{~m}$, with 90th-percentile values greater than $7 \mathrm{~m}$. These studies also noted the relatively uniform spatial wave climate across the region, although it was noted that the highest waves existed in the Indian Ocean sector and that Drake Passage had a significant impact in reducing the wave climate east of the passage.

These satellite datasets were expanded by Young (1998b) who pooled 10 years of data from Geosat, TOPEX, ERS-1, and ERS-2 and also combined with European Centre for Medium Range Weather Forecasts numerical model data to provide wave period and direction data. This combined dataset confirmed the wave climate results of the previous studies and also showed the significant influence of swell generated in the region in defining the wave climate of the Pacific and Indian Oceans. The role of the Southern Ocean as a generation source for swell was later confirmed in the detailed model studies of Alves (2006) and Semedo et al. (2011).

In situ buoy measurements in the Southern Ocean are very limited. Steedman (1993) reported on a 1-yr deployment of a nondirectional wave buoy at Macquarie Island $\left(54.5^{\circ} \mathrm{S}, 158.8^{\circ} \mathrm{E}\right)$ without providing any detailed analysis of the data. Hemer (2010) reported on a long-term nondirectional buoy deployment at Cape Sorell $\left(42^{\circ} \mathrm{S}, 144^{\circ} \mathrm{E}\right)$ on the western coast of Tasmania spanning 23 years. Rather than considering wave climate or spectral form, this study concentrated on changes in storminess over the period. More recently, Rapizo et al. (2015) reported on directional data recorded at the Southern Ocean Flux Station (SOFS; $46.7^{\circ} \mathrm{S}$, $142.0^{\circ} \mathrm{E}$ ) (Schulz et al. 2011, 2012). The total duration of the data analyzed was 23 months spread over three deployments spanning 3 years. The analysis provided the first detailed investigation of spectral shape of Southern Ocean waves. Barbariol et al. (2019) recently considered extreme waves measured from both moored and drifting buoys in the Southern Ocean.

\section{Datasets}

Three separate datasets have been analyzed in this study. These consist of a 33-yr satellite altimeter dataset spanning the period 1985-2018, a combined dataset from five in situ buoys, and output from the WAVEWATCH III model, run for the same periods as the in situ buoy data. The details of each of these datasets are reported below.

\section{a. Altimeter data}

Satellite radar altimeters have provided almost continuous global coverage, measuring $H_{s}$ and wind speed $U_{10}$ since 1985 (a break during 1990-91). During this period, a total of 13 such satellite missions have been operational. A combined dataset, consistently calibrated and validated against an extensive network of wave buoys has been reported by Young et al. (2017) and Ribal and Young (2019). Satellite altimeters are typically placed in near polar orbits, meaning that at any location there will be ascending passes (south to north) and descending passes (north to south) measuring $H_{s}$ and $U_{10}$ approximately every $7 \mathrm{~km}(1 \mathrm{~s})$ below the satellite track. Each measurement is an average over an approximate $8 \mathrm{~km}$ diameter footprint. Although the along-track resolution is relatively high $(\sim 7 \mathrm{~km})$ the distance between ground tracks is typically $100 \mathrm{~s}$ of $\mathrm{km}$. Therefore, to ensure there is sufficient data to form stable statistics, the data are typically pooled into regions $2^{\circ} \times 2^{\circ}$. This dataset and the approach of using $2^{\circ}$ aggregation regions have been extensively used in a number of applications including Young and Donelan (2018) (climatology); Young et al. (2011), Young and Ribal (2019), and Meucci et al. (2020) (long-term trends); and Takbash et al. (2019), Takbash and Young (2019), and Meucci et al. (2018) (extreme value estimates). For this study, the Ribal and Young (2019) database, aggregated into $2^{\circ}$ regions has been used. 


\section{b. In situ buoys}

The five in situ buoys used in this analysis are shown in Fig. 1. To the best of our knowledge, these cover all of the deep-water moored buoy locations where wave spectra have been recorded. Note that there have also been some drifting buoys in the Southern Ocean (Barbariol et al. 2019). The details of the buoy type, data periods considered, and sampling details are summarized in Table 1.

The SOFS (Schulz et al. 2011, 2012; Rapizo et al. 2015) is a $2.7-\mathrm{m}$-diameter meteorological buoy that was deployed in a water depth of $4500 \mathrm{~m}$ at $46.7^{\circ} \mathrm{S}, 142.0^{\circ} \mathrm{E}$, south of Tasmania. Data analyzed here span the period from November 2011 to January 2016, although the record is not continuous and contains a number of lengthy gaps. The buoy had a sonic anemometer at a height of $3.52 \mathrm{~m}$ and two different directional accelerometer packages (waves). A motion reference unit (MRU) (Rapizo et al. 2015) and a Triaxys package (MacIsaac and Naeth 2013) were deployed on the buoy. Because the Triaxys package was not deployed for the full period considered here, the MRU was used for all data analysis (see Table 1). Note that in September of 2012 the SOFS buoy broke its mooring and drifted until it was recovered in January of 2013 (Rapizo et al. 2015). Although data are available from this period, they have not been used in this study.

A Datawell Waverider buoy (http://www.datawell.nl/) was deployed northeast of Macquarie Island $\left(54.5^{\circ} \mathrm{S}\right.$, $158.8^{\circ} \mathrm{E}$ ) in $130 \mathrm{~m}$ water depth from November 1988 to October 1989 (Steedman 1993). In addition, a meteorological station with an anemometer at a reference height of $3.1 \mathrm{~m}$ was located on the Island. The buoy was nondirectional but recorded a full 12 months of data (see Table 1).

Farther west of Macquarie Island, a Triaxys buoy has been deployed by Metocean Solutions (https:// www.metocean.co.nz/) south of Campbell Island (52.5 S, $169.1^{\circ} \mathrm{E}$ ) in approximately $150 \mathrm{~m}$ of water. The data analyzed in this paper span the period from February 2017 to October 2017. Unlike the other deployments, the time series measured by the buoy were not available and hence the directional spectra processed onboard the buoy have been used in this analysis (see Table 1).

The Ocean Observatories Institute (https://oceanobservatories. org/) deployed 3-m-diameter meteorological buoys in approximately $4500-\mathrm{m}$ water depth on either side of South America (OOI1: $54.5^{\circ} \mathrm{S}, 271.0^{\circ} \mathrm{E}$; OOI2: $43.0^{\circ} \mathrm{S}$, $317.5^{\circ} \mathrm{E}$ ) (see Fig. 1). Data were analyzed for the periods from February 2015 to December 2015 (OOI1) and from March 2015 to November 2015 (OOI2). These buoys both had a Triaxys directional accelerometer package onboard.

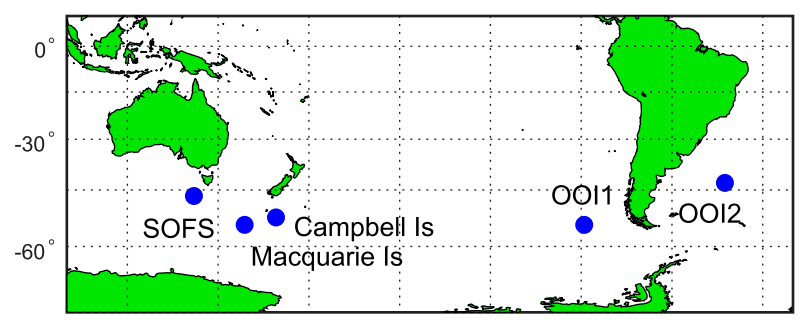

FIG. 1. Locations of the in situ buoy sites in the Southern Ocean: SOFS-Southern Ocean Flux Station, Macquarie Island, Campbell Island, OOI1-Ocean Observatories Institute Buoy 1, and OOI2-Ocean Observatories Institute Buoy 2.

Data from all instruments were processed to obtain directional spectra [for Macquarie Island, one-dimensional (1D) spectra] and, where available (SOFS, Macquarie Island, and Campbell Island), coincident wind speed at a reference height of $10 \mathrm{~m}$. All wind data were corrected to this reference height by assuming a neutral logarithmic boundary layer (Young and Donelan 2018).

\section{c. Model hindcasts}

The WAVEWATCH III spectral wave model (WW3DG 2016) was run for each of the periods covered by the in situ measurements summarized in Table 1 . The purpose of these runs was not to validate the model but to use the model as an aid in interpreting the physical processes active in producing the recorded spectra. As such, our focus is the examination of the source terms representing the physical processes within the model. In this regard, the model represents the evolution of the wave action density spectrum $N(k, \theta ; \mathbf{x}, t)=F(k, \theta ; \mathbf{x}, t) / \omega$ as

$$
\frac{d N}{d t}=\frac{S_{\mathrm{tot}}}{\omega}
$$

where $S_{\text {tot }}=S_{\text {in }}+S_{\mathrm{swl}}+S_{\mathrm{nl}}+S_{\mathrm{wc}}$ and $S_{\mathrm{in}}$ represents the wind input, $S_{\mathrm{swl}}$ is the swell decay, $S_{\mathrm{nl}}$ is the nonlinear interactions, and $S_{\mathrm{wc}}$ is the white-cap dissipation (Liu et al. 2019). In the above, $F$ represents the energy density spectrum, which is a function of wavenumber $k$, direction $\theta$, the spatial vector, $\mathbf{x}$, and time $t$. The intrinsic frequency is given by $\omega=(g k)^{1 / 2}$. The source terms $S_{\text {tot }}$ are represented by the ST6 package originally described in Rogers et al. (2012) and Zieger et al. (2015) and recently updated by Liu et al. (2019).

The model was run over a global domain bounded by latitudes $78^{\circ} \mathrm{S}$ and $78^{\circ} \mathrm{N}$ with a spatial resolution of $0.5^{\circ} \times 0.5^{\circ}$. The resolution of the spectral grid was $\Delta f / f=$ 0.1 , where $\omega=2 \pi f$ and $\Delta \theta=10^{\circ}$, with frequencies ranging from $f=0.037$ to $0.953 \mathrm{~Hz}$. Ice-infested grid cells with an ice concentration $C_{I}>75 \%$ are considered as land points, and grid cells with $C_{I}<25 \%$ are regarded as open ocean (Tolman 2003). At points between these 
TABLE 1. Details of in situ buoy data. The columns show the buoy name, type of data [directional (dir) or nondirectional (nondir)], latitude and longitude, duration of data analyzed, duration and sampling rate of time series analyzed, and data frequency.

\begin{tabular}{lllllll}
\hline \multicolumn{1}{c}{ Buoy name } & Type & \multicolumn{1}{c}{ Lat, lon } & \multicolumn{1}{c}{ Data type } & \multicolumn{1}{c}{ Duration } & Sampling duration/rate & Data frequency \\
\hline SOFS & Dir & $46.7^{\circ} \mathrm{S}, 142.0^{\circ} \mathrm{E}$ & 2D spectra; $U_{10}$ & Nov 2011-Jan 2016 & $10 \mathrm{~min} @ 4 \mathrm{~Hz}$ & 1-hourly \\
Macquarie Island & Nondir & $54.5^{\circ} \mathrm{S}, 158.8^{\circ} \mathrm{E}$ & 1D spectra; $U_{10}$ & Nov 1988-Oct 1989 & $17 \mathrm{~min} @ 1 \mathrm{~Hz}$ & 3-hourly \\
Campbell Island & Dir & $52.5^{\circ} \mathrm{S}, 169.1^{\circ} \mathrm{E}$ & 2D spectra & Feb-Oct 2017 & 20 min @ 4 Hz (processed on buoy) & 3-hourly \\
OOI1 & Dir & $54.5^{\circ} \mathrm{S}, 271,0^{\circ} \mathrm{E}$ & 2D spectra & Feb-Dec 2015 & 20 min @ 1.28 Hz & 1-hourly \\
OOI2 & Dir & $43.0^{\circ} \mathrm{S}, 317.5^{\circ} \mathrm{E}$ & 2D spectra & Mar-Nov 2015 & 20 min @ 1.28 Hz & 1-hourly \\
\hline
\end{tabular}

limits, the wave energy flux is partially blocked, with the amount of blocked varying linearly between 0 and 1 .

For the hindcast associated with the period of the Macquarie Island dataset (1988-89) the model was forced with $0.5^{\circ}$ resolution CFSR winds and ice concentration (Saha et al. 2010). For the other periods, CFSv2 data at $0.2^{\circ}$ resolution (Saha et al. 2014) were used. Not also that currents were not included in the hindcasts, and hence wave-current interactions are ignored (Rapizo et al. 2018).

\section{Seasonal wind and wave climate}

The altimeter data were binned into $2^{\circ} \times 2^{\circ}$ bins, and the monthly means and upper percentiles were determined for both wind speed and significant wave height. Global climatologies of wind speed and wave height have been produced previously (Young 1994a, 1999, 1998b; Young and Holland 1996; Young and Donelan 2018); however, this analysis focuses specifically on the Southern Ocean. Figure 2 shows shaded color plots of mean monthly and 90th-percentile wind speeds, $U_{10}$ and $U_{10}(90)$, respectively. The distributions for both January (summer) and July (winter) are shown. Figure 3 similarly shows the mean monthly and 90th-percentile significant wave height: $\overline{H_{s}}$ and $H_{s}(90)$, respectively.

There are several striking features of these figures. The first is how uniform the wind climate is across the Southern Ocean (Fig. 2). There is a region between Australia and South Africa (Indian Ocean sector) where there is a wind speed maximum. However, the distribution around the Southern Ocean is remarkably uniform. The persistent westerlies that blow around the Southern Ocean produce this consistent wind field (at least at the level of monthly mean statistics). The wind speed peak occurs at approximately $50^{\circ} \mathrm{S}$, with this latitude moving slightly north during the Southern Hemisphere winter. There is a seasonal variation in the strength of the winds but nowhere near as large as seen at similar latitudes in the Northern Hemisphere (Young 1994a, 1999; Young and Donelan 2018). The data indicate that $\overline{U_{10}}$ varies between 11 (summer) and 13 (winter) $\mathrm{m} \mathrm{s}^{-1}$, with $U_{10}(90)$ varying between 15 (summer) and 18 (winter) $\mathrm{m} \mathrm{s}^{-1}$. The wave-height climate (Fig. 3) largely mirrors the distribution of wind speeds with a remarkably uniform distribution of waves around the Southern Ocean and only a relatively small variation winter to summer (when compared with the Northern Hemisphere). Values of $\overline{H_{s}}$ vary between 4 (summer) and 5 (winter) $\mathrm{m}$, with $H_{s}(90)$ ranging between 5.5 (summer) and 7 (winter) $\mathrm{m}$. There is a clear "wave shadow" east of South America. At the 90th percentile this shadow is extensive, extending for $30^{\circ}$ of longitude. Because a similar reduction in winds is not apparent, this reduction in wave conditions is presumably due to the blockage of swell propagating from the west and the reduced fetch eastward of South America.

\section{Wind and wave-height extremes}

\section{a. Altimeter extreme value analysis}

Takbash et al. (2019) and Takbash and Young (2019) have shown that altimeter datasets such as that used here can be used to estimate extreme values of wind speed and wave height. For instance, the 100-yr-returnperiod values of wind speed and wave height $\left(U_{10}^{100}\right.$ and $H_{s}^{100}$, respectively) can be estimated. With a time series of length 33 years, it is possible to apply a peaks-overthreshold approach in which a generalized Pareto distribution is fitted to peaks above a defined threshold as indicated below:

$$
F(x)=1-\left[1+k\left(\frac{x-A}{B}\right)^{-1 / k}\right],
$$

where $F(x)$ is the probability distribution function (pdf), $x$ is the environmental parameter under consideration $\left(U_{10}\right.$ or $\left.H_{s}\right), k$ and $B$ are shape and scale parameters, respectively, and $A$ is the chosen threshold. Following Takbash et al. (2019) the 90th percentile was chosen as the threshold value. Following extreme value theory (Coles 2001) independent data above the threshold were selected. To ensure the data selected are independent, only values separated in time by at least $48 \mathrm{~h}$ were considered (Caires and Sterl 2005). 

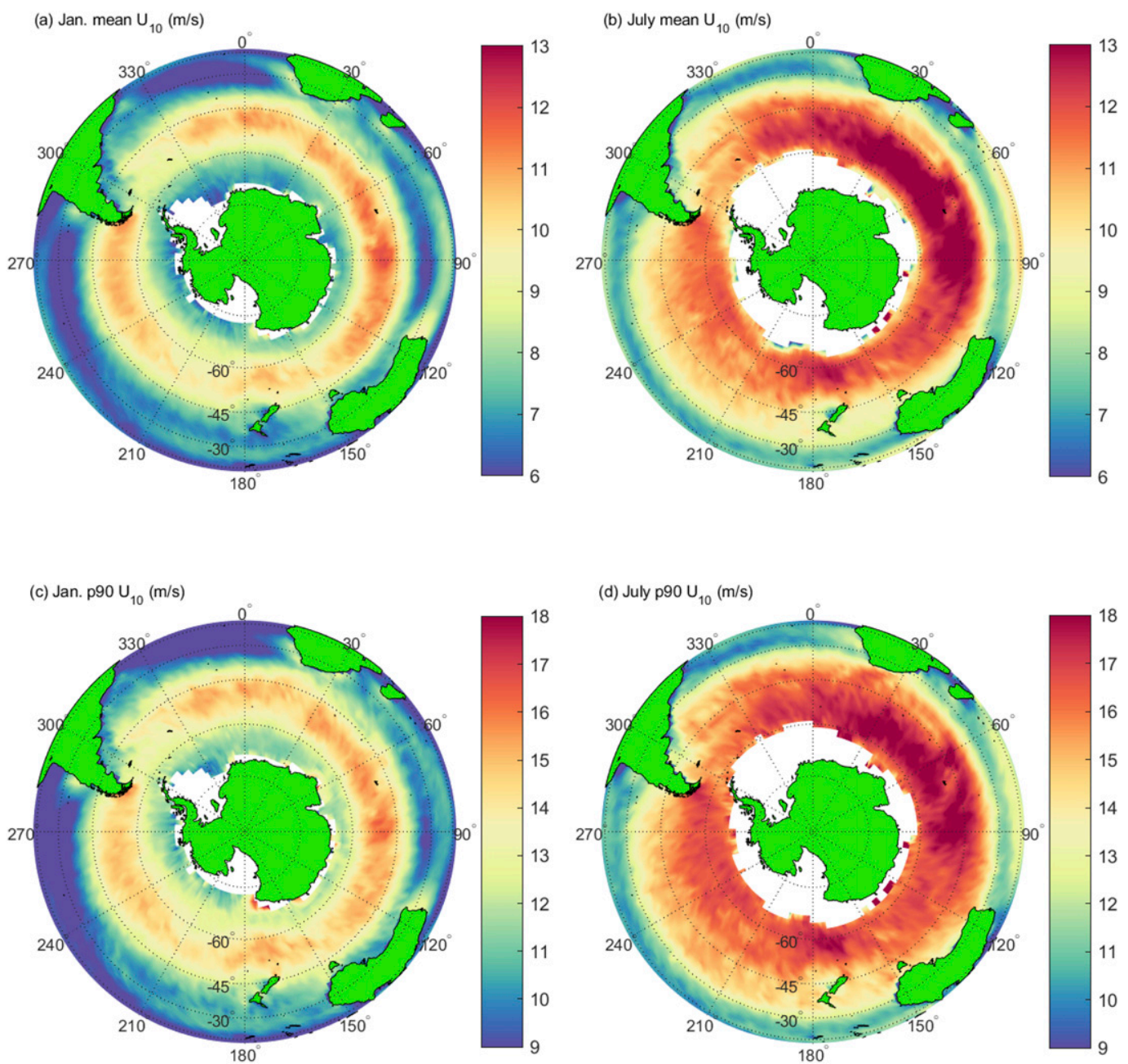

FIG. 2. Mean and 90th-percentile monthly wind speed $U_{10}$ from altimeter data $\left(\mathrm{m} \mathrm{s}^{-1}\right)$ : (a) mean monthly wind speed $\overline{U_{10}}$ in January, (b) $\overline{U_{10}}$ in July, (c) 90th-percentile monthly wind speed $U_{10}(90)$ in January, and (d) $U_{10}(90)$ in July.

Figure 4 shows contour plots of 100-yr-return-period values of wind speed and $H_{s}$. As is typical for such extreme value estimates obtained from a finite length time series (33 years), the confidence limits on the extreme estimates mean that the contour plots in Fig. 4 exhibit some noise. Despite this, clear spatial distributions are evident and Takbash et al. (2019) have shown that such altimeter estimates of extremes agree well with longduration buoy measurements. As with the monthly climatology, the area with the maximum extreme wind speed and $H_{s}$ extremes is in the Indian Ocean sector where $U_{10}^{100} \approx 35 \mathrm{~m} \mathrm{~s}^{-1}$ and $H_{s}^{100} \approx 18 \mathrm{~m}$. However, as also seen for the mean climatology (Figs. 2 and 3), there is a remarkably consistent distribution of extreme values around the Southern Ocean that peaks at approximately $50^{\circ} \mathrm{S}$. However, it is clear that this band moves south as one moves clockwise from South America. This is particularly the case for wind speed. To the east of South America, the maximum values are at $38^{\circ} \mathrm{S}$. This latitude gradually increases (moves farther south) as one moves clockwise around the Southern Ocean. West of South America this band of extreme winds is south of $60^{\circ} \mathrm{S}$. The same patterns can be seen in the distribution of $H_{s}^{100}$, although there is now a reduction in the magnitude of the extreme wave conditions east of South America, again due to the shading provided by South America. Drake Passage appears to reduce the magnitude of both mean monthly and extreme wave conditions.

Although extreme winds and waves in the Southern Ocean, as shown in Fig. 4, are clearly large, Takbash et al. (2019) show that the North Atlantic actually produces even higher extremes. This is probably a result of the proximity of land that results in more intense low pressure systems. 

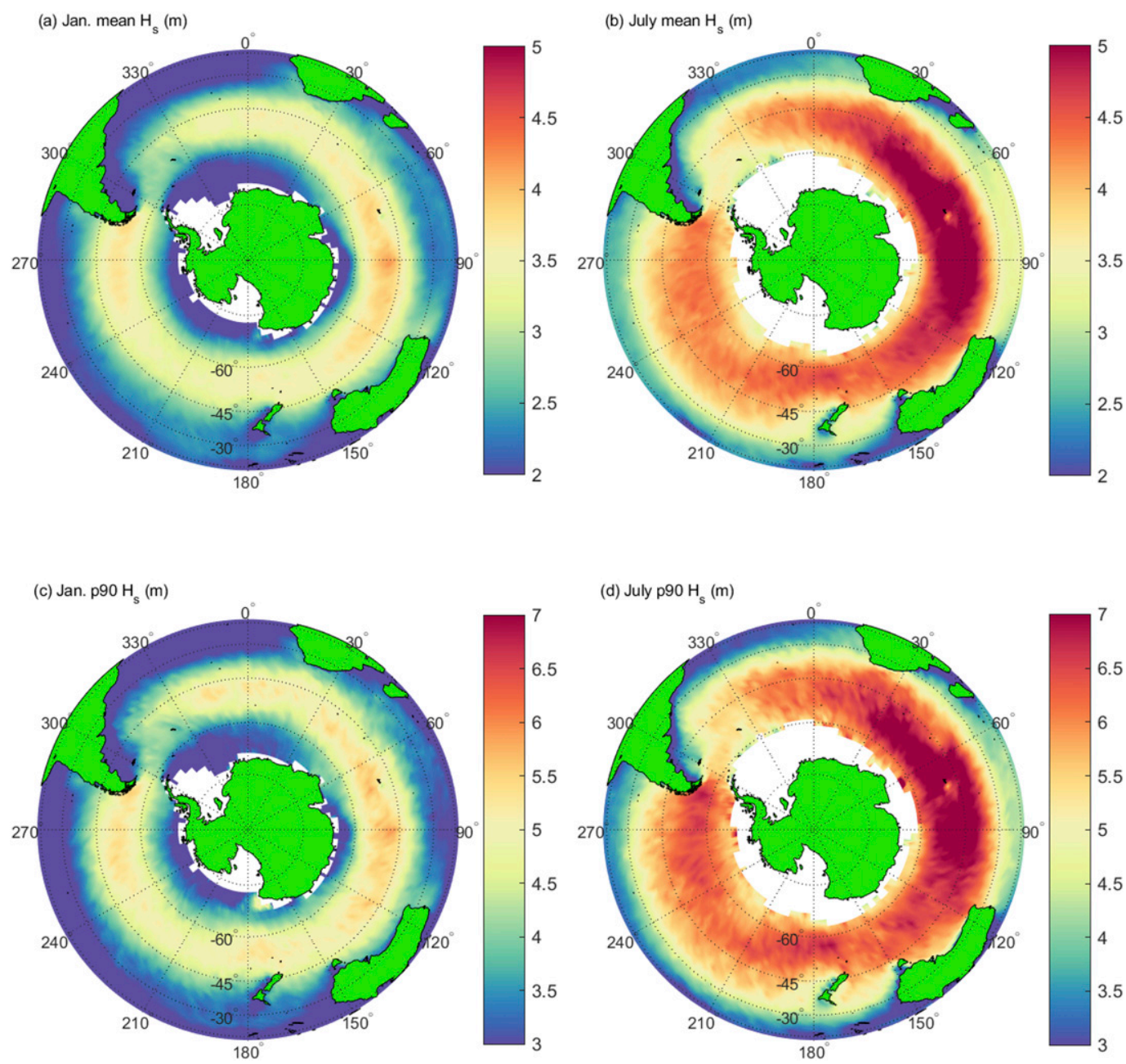

FIG. 3. Mean and 90th percentile monthly significant wave height $H_{s}$ from altimeter data (m): (a) mean monthly significant wave height $\overline{H_{s}}$ in January, (b) $\overline{H_{s}}$ in July, (c) 90th-percentile monthly significant wave height $H_{s}(90)$ in January, and (d) $H_{s}(90)$ in July.

\section{b. Maximum individual wave heights}

As noted in section $3 \mathrm{~b}$ and Table 1 , none of the in situ records are long enough to carry out extreme value analysis. However, examination of the maximum values of $H_{s}$ recorded at each buoy yields $15.6 \mathrm{~m}$ for SOFS (28 April 2012), 10.6 m for Macquarie Island (13 May 1989), $11.7 \mathrm{~m}$ for Campbell Island (19 May 2017), $12.5 \mathrm{~m}$ for OOI1 (16 August 2015), and 10.2 m OOI2 (18 June 2015). None of these values is inconsistent with $H_{s}^{100} \approx$ $18 \mathrm{~m}$ as determined from the altimeter record. The recorded in situ data provide the opportunity to examine the maximum individual wave height recorded at each of these locations. Noting that these buoys record the water surface acceleration rather than the displacement, it is first necessary to determine the water surface displacement by double integration of the acceleration record. This is most effectively achieved in the frequency domain, using the relationship from linear wave theory in the absence of currents,

$$
X_{s}(f)=X_{a}(f) / \omega^{2},
$$

where $X_{s}(f)$ and $X_{a}(f)$ are the Fourier transforms of the surface displacement and acceleration, respectively. The process used to determine the surface displacement time series is 1) determine $X_{a}(f)$ from the acceleration record, 2) high-pass filter the record, 3) apply Eq. (3) to determine $X_{s}(f)$, and then 4$)$ evaluate the inverse Fourier transform to determine the surface displacement $\eta$. Note that the application of Eq. (3) enhances low-frequency noise in the record (i.e., small values of $\omega)$; therefore, it is necessary to high-pass filter the record to remove this noise. Following some experimentation, this was achieved by removing energy below $f=0.03 \mathrm{~Hz}$ in $X_{s}(f)$, before applying the inverse Fourier transform. 

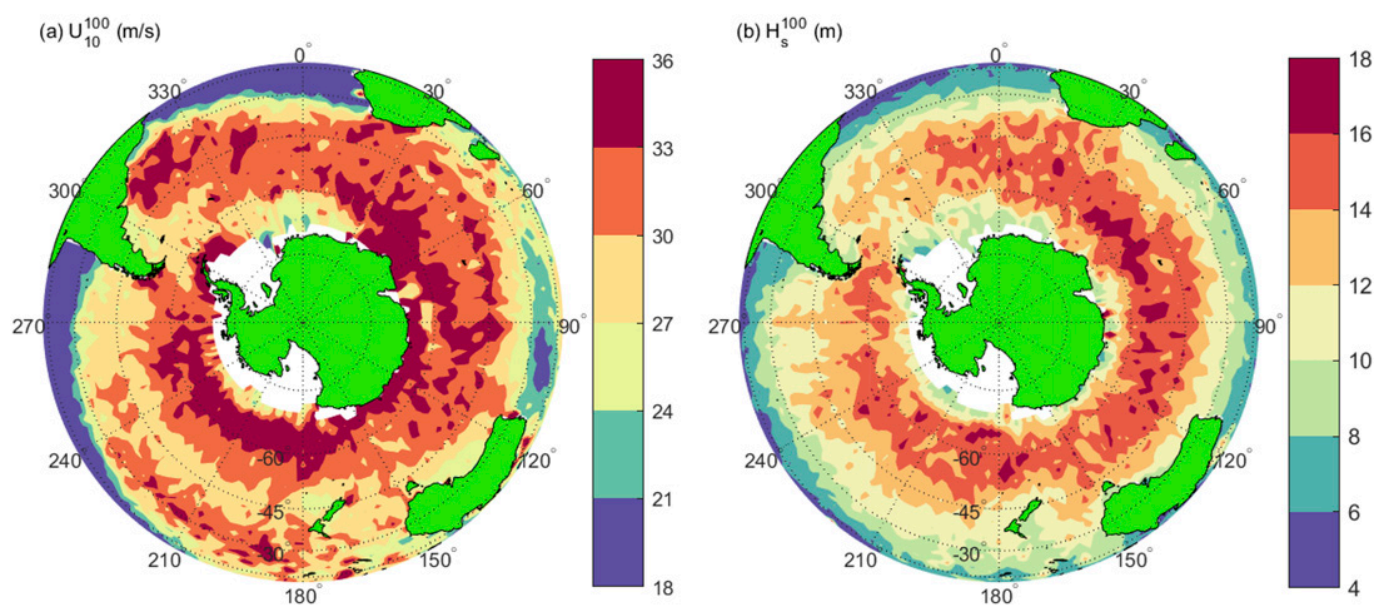

FIG. 4. Extreme values of wind speed and $H_{s}$ : 100 -yr-return-period (a) $U_{10}^{100}\left(\mathrm{~m} \mathrm{~s}^{-1}\right)$ and (b) $H_{s}^{100}(\mathrm{~m})$.

Figure 5 shows the time series of the water surface displacement constructed in this manner for the SOFS case with $H_{s}=15.6 \mathrm{~m}$ on 28 April 2012. The figure shows the full time series, the region around the maximum individual wave, and variation in $H_{s}$ in the days before and after the event on 28 April 2012. The largest individual wave in the record has a crest-to-trough height of $H=26.4 \mathrm{~m}$. The event was associated with an intense low pressure system that propagated across the Southern Ocean (also see section 7 and Fig. 11). Although this is clearly a very large wave, the ratio $H / H_{s}=1.7$, which is less than the limit of 2 commonly used to signify a rogue or freak wave. Hence, such a wave height is not unexpected for a wave record with such an $H_{s}$. To the best of our knowledge, this is the largest individual wave recorded from the Southern Ocean. Metocean Solutions (https://www.metocean.co.nz/news/2018/5/9/a-record-waveheight-measured-in-the-southern-ocean) reported in the media on a case from the Campbell Island buoy recorded on 9 May 2018 in which $H=23.8 \mathrm{~m}$ in a record with $H_{s}=$ $14.9 \mathrm{~m}\left(H / H_{s}=1.6\right)$. This was not within the time period of the Campbell Island buoy analyzed in this study. Note also that the acceleration time series is not available from the Campbell Island buoy, and this recorded value was determined by the onboard Triaxys analysis software, the details of which are not clearly documented. Noting that our extreme value analysis indicates $H_{s}^{100} \approx 18 \mathrm{~m}$, meaning that individual waves close to $30 \mathrm{~m}$ may occur in the Southern Ocean.

\section{Wave spectra}

\section{a. Nondirectional form}

The time series of vertical acceleration at each of the in situ sites was analyzed to determine the water surface energy density spectrum $E(f)$ and the integral parameters of $H_{s}=4\left[\int E(f) d f\right]^{1 / 2}$ and peak spectral frequency $f_{p}$. In the case of Campbell Island, the spectra processed onboard the buoy were used. Figure 6 shows typical examples of $E(f)$ from SOFS, Campbell Island, and OOI2. With the exception of cases in which there were very light winds, the 1D energy spectra recorded at SOFS, Macquarie Island, Campbell Island, and OOI1 are typically unimodal with a high-frequency face that is approximately proportional to $f^{-4}$. Values of $f_{p}$ are almost always less than $0.1 \mathrm{~Hz}$ and are typically $0.07 \mathrm{~Hz}$ or lower. There are very few cases in which spectra are clearly bimodal with distinct swell and wind-sea peaks.

The spectra at OOI2 are distinctly different, with many more cases with either a broad spectral peak region (see Fig. 6c) or clearly multipeaked spectra. This suggests that, at this location, the wave shadow east of South America (see Figs. 1 and 3), has a clear impact on the spectral form.

Noting the generally unimodal structure of the 1D energy spectra, the generalized JONSWAP form proposed by Young and Verhagen (1996) was fitted to the spectra:

$$
\begin{aligned}
E(f)= & \beta g^{2}(2 \pi)^{-4} f_{p}^{-(5+n)} f^{n} \exp \left[\frac{n}{4}\left(f / f_{p}\right)^{-4}\right] \\
& \times \gamma^{\exp \left[-\left(f-f_{p}\right)^{2} /\left(2 \sigma^{2} f_{p}^{2}\right)\right]} .
\end{aligned}
$$

In the spectral form of Eq. (4), $g$ is gravity and the spectral parameters are $\beta$ (a "Phillips" scale parameter), $f_{p}$ (the spectral peak frequency), $n$ (the high-frequency spectral decay exponent), and $\sigma$ (the spectral width parameter). This form differs from the classic JONSWAP form in that the exponent $n$ is not set to a constant (e.g., $n=-5$ for JONSWAP). The nondimensional energy $\varepsilon$ and nondimensional frequency $\nu$ were then determined as 

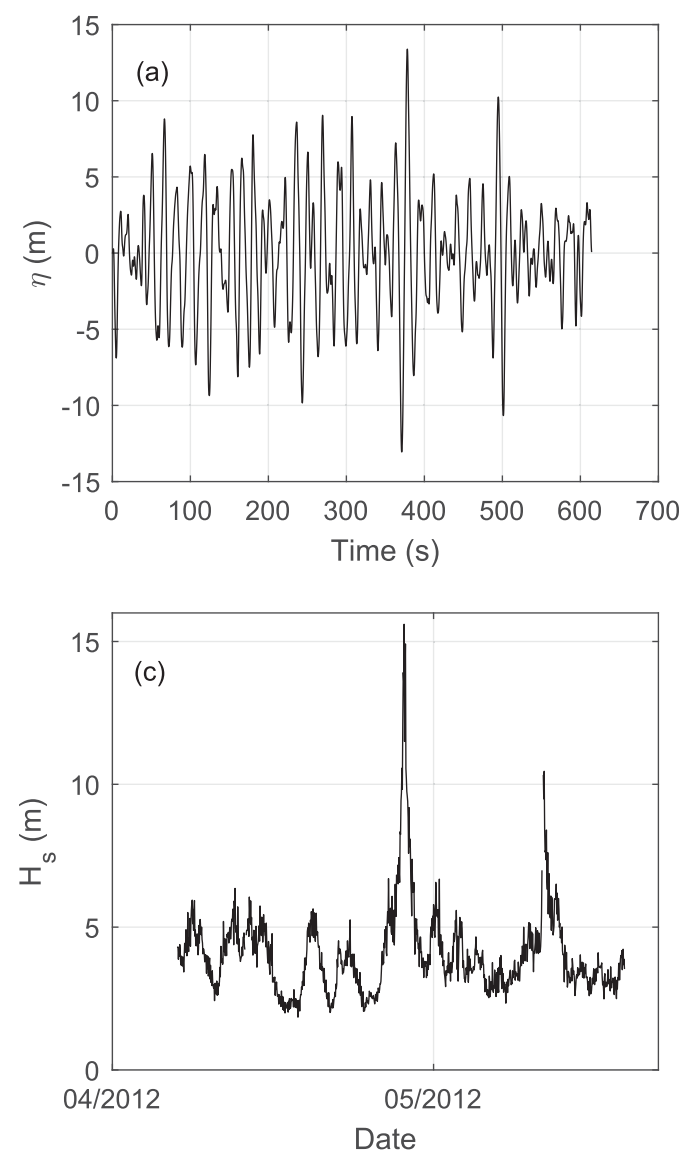

$$
\begin{aligned}
& \varepsilon=g^{2} E_{\mathrm{tot}} / U_{10}^{4} \text { and } \\
& \nu=f_{p} U_{10} / g,
\end{aligned}
$$

where

$$
E_{\mathrm{tot}}=\int E(f) d f \text {. }
$$

Figures 7 and 8 show data from the SOFS buoy and Macquarie Island. Figures $7 \mathrm{a}$ and $8 \mathrm{a}$ show the nondimensional energy $\varepsilon$ as a function of the nondimensional peak frequency $\nu$. Also shown in these plots is the fetchlimited relationship between $\varepsilon$ and $\nu$ proposed by Donelan et al. (1985) $\left(\varepsilon=6.365 \times 10^{-6} \nu^{-3.3}\right)$. Although the present waves are clearly not fetch-limited, there is remarkable agreement between the data and this fetch-limited relationship. The vertical line shown in Figs. 7a and 8a, drawn at $\nu=0.13$, is the fully developed limit proposed by Donelan et al. (1985). Typically, waves with $\nu<0.13$ are regarded as swell and are not receiving active energy input at the spectral peak from the local wind. The vast majority of the data in Figs. 7a and 8a fall into this category.

Values of the spectral parameters $\eta, \beta$, and $\gamma$ are shown in Figs. 7 and $8 b-d$, respectively. Figures $7 b$ and $8 b$ show histograms of the values of $n$. Although there is clearly a spread of values, the median value is $n \approx-4$, consistent

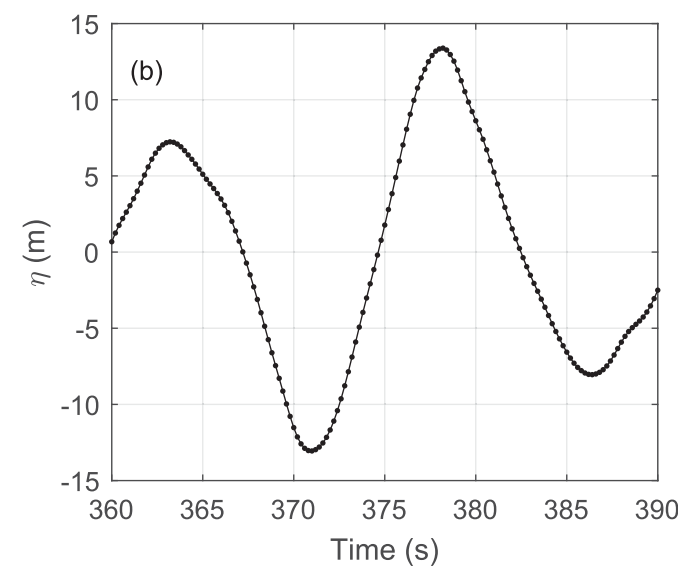

FIG. 5. Wave-height records at the SOFS buoy: (a) water surface elevation record $\eta$ at 0600 UTC $28 \mathrm{Apr}$ 2012 , (b) the portion of the time series in (a) around the maximum recorded wave (trough-to-crest wave height $H=26.4 \mathrm{~m}$ ), and (c) variation of $H_{s}$ during April and May 2012. The event shown in (a) and (b) can be seen with $H_{s}=15.6 \mathrm{~m}$.

with numerous studies of wind generated waves. The values of $\beta$ and $\gamma$ are shown in Figs. 7 and $8 \mathrm{c}, \mathrm{d}$ as a function of the inverse wave age $U_{10} / C_{p}$, where $C_{p}$ is the phase speed of the spectral peak. Also shown on these plots are the fetch-limited results of Donelan et al. (1985) $\left[\beta=0.006\left(U_{10} / C_{p}\right)^{0.55}\right.$ and $\left.\gamma=1.7\right]$. The value of $\gamma=1.7$ corresponds to the fully developed limit proposed by Donelan et al. (1985). Also shown in Figs. 7 and 8 is the generally accepted demarcation between wind sea and swell of $U_{10} / C_{p}=0.83$. Values $U_{10} / C_{p}<0.83$ signify waves that are not receiving direct energy input from the wind and are usually considered as swell. Again, almost all the data are for $U_{10} / C_{p}<0.83$ and hence one would normally consider them as swell. Despite this, the spectral form is very similar to what would normally be expected in actively wind generated seas.

The results shown in Figs. 7 and 8 are consistent for the four buoy locations west of South America. In fact, the 1D spectral parameters across these four locations are almost identical. This is consistent with the altimeter results of Fig. 3, which showed that the wave climate is remarkably spatially homogeneous across the Southern Ocean.

The results shown in Figs. 7 and 8 indicate that although the spectra have many similarities with fetch-limited 

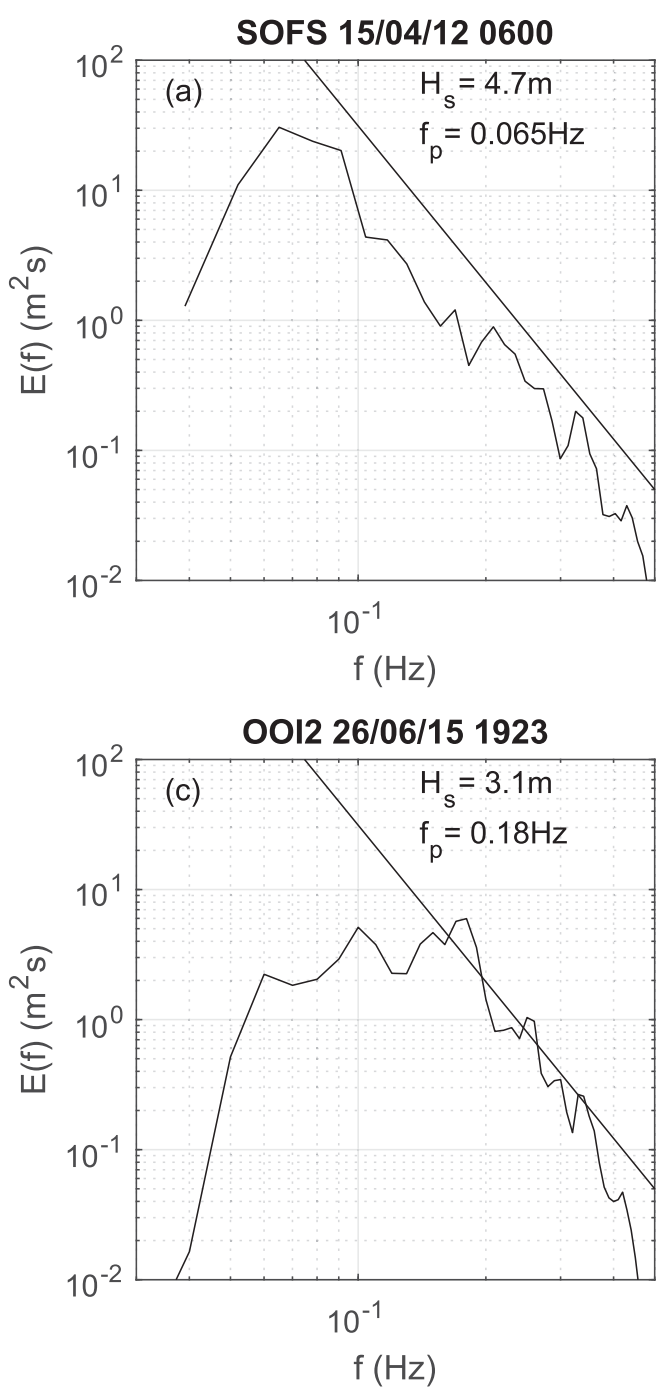

spectra, the details, and probably the physical processes responsible for their generation are very different. Like fetch-limited wind seas, Southern Ocean waves have a high-frequency spectral form approximately proportional to $f^{-4}$. The spectra are also unimodal with no obvious separate swell peak(s). The spectral peak is, however, at very low frequencies. In most cases $f_{p}<0.07 \mathrm{~Hz}$. As a result, values of $U_{10} / C_{p}<1$, and hence it is likely that no wind input occurs at or near the spectral peak. Although the 1D spectra can be modeled by the generalized JONSWAP form in Eq. (4), the values of $\beta$, the equilibrium range constant, are significantly less than for fetch-limited wind seas (see Figs. 7c and 8c). As a result the nondimensional energy, $\varepsilon$ is smaller than one would associate with fetch-limited wind seas (see Figs. 7a and 8a).

The results above indicate that the detailed source term balance in Eq. (1) for such Southern Ocean waves must be very different to fetch-limited wind seas. This will be

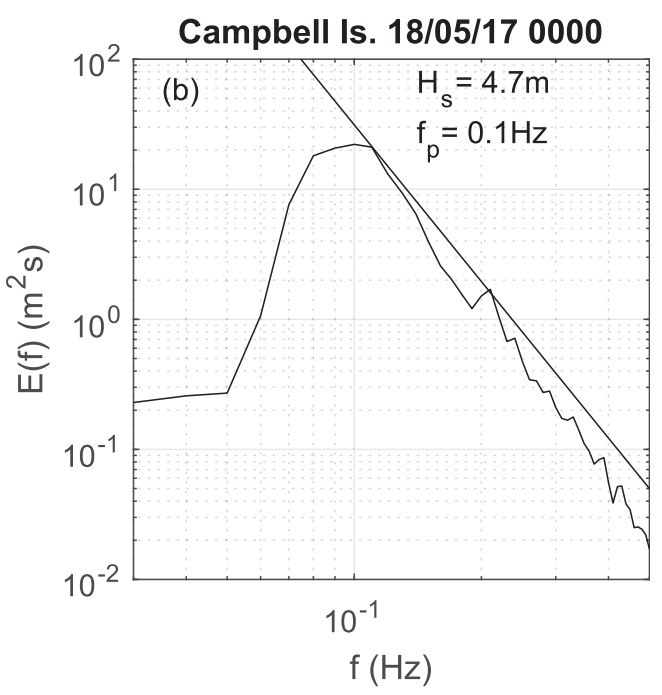

FIG. 6. Examples of 1D energy density spectra $E(f)$ (the sloping solid line has a slope of $f^{-4}$ ): (a) SOFS buoy at 0600 UTC 15 Apr 2012, (b) Campbell Island at 0000 UTC 18 May 2017, and (c) OOI2 buoy at 1923 UTC 26 Jun 2015.

explored in more detail in section 7. In the above analysis, we have excluded the data from OOI2, as many of the spectra at this site were bimodal with a clear separate swell peak. As such, these spectra are not well modeled by the generalized JONSWAP form in Eq. (4). The physical processes active at this site will be considered further in section 7.

\section{b. Directional spreading}

With the exception of Macquarie Island, all other sites provided directional data, enabling an analysis of directional spreading. Following Longuet-Higgins et al. (1963) we define the direction spectrum $E(f, \theta)$ as

$$
E(f, \theta)=E(f) D(f, \theta),
$$

where $D(f, \theta)$ is a directional spreading function, defined such that $\int D(f, \theta) d \theta=1$. 

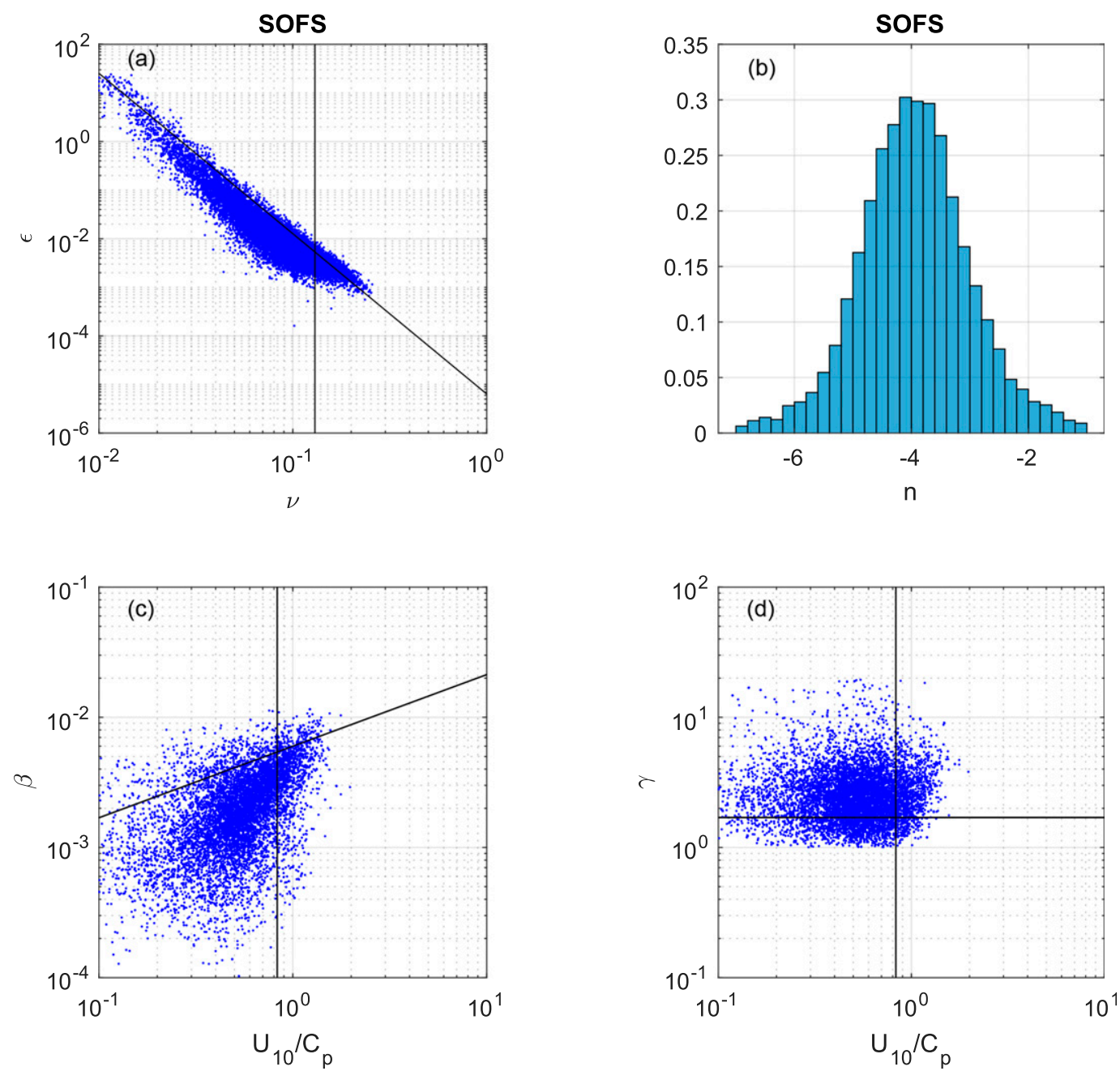

FIG. 7. Spectral parameters recorded at the SOFS buoy: (a) Nondimensional energy $\varepsilon$ [ Eq. (5)] vs nondimensional peak frequency $\nu$ [Eq. (6)]. The solid line is the fetch-limited result of Donelan et al. (1985). (b) Histogram of the recoded values of $n$ in the relation Eq. (4). (c) The parameter $\beta$ from Eq. (4) as a function of the inverse wave age $U_{10} / C_{p}$. The sloping line is the fetch-limited result of Donelan et al. (1985), and the vertical line is the demarcation between swell and wind sea, $U_{10} / C_{p}=0.83$. (d) The parameter $\gamma$ from Eq. (4) as a function of $U_{10} / C_{p}$. The horizontal line, $\gamma=1.7$, is the fetch-limited fully developed result of Donelan et al. (1985), and the vertical line is the demarcation between swell and wind sea, $U_{10} / C_{p}=0.83$.

As directional wave buoys measure only the three components of acceleration, determination of the full directional spreading function, $D(f, \theta)$ requires additional assumptions. Numerous techniques have been proposed for such solutions, including the Fourier expansion method (Longuet-Higgins et al. 1963), maximum likelihood method (Isobe et al. 1984), maximum entropy method (Lygre and Krogstad 1986), and the wavelet decomposition method (Krogstad et al. 2006). A summary of these approaches and their advantages and disadvantages can be found in Young (1994b). Noting that for the Campbell Island buoy the directional spectra were determined onboard using the maximum entropy method, this approach was adopted for the spectra at all locations. As with the $1 \mathrm{D}$ spectra, the spreading functions obtained across all of the in situ buoy sites were very similar. A typical example appears in Fig. 9 for Campbell Island.

As with the 1D spectra, the directional spreading has many characteristics in common with fetch-limited wind sea spectra. The mean directions are typically west to southwest (meteorological convention-coming from), consistent with the prevailing westerly winds in the area. The spectra tend to be narrowest at the spectral peak frequency $f_{p}$ and broaden with increasing frequency. There is a tendency for the directional spreading to become directionally bimodal at frequencies above 2.5 $f_{p}$ (Young et al. 1995; Ewans 1998). 

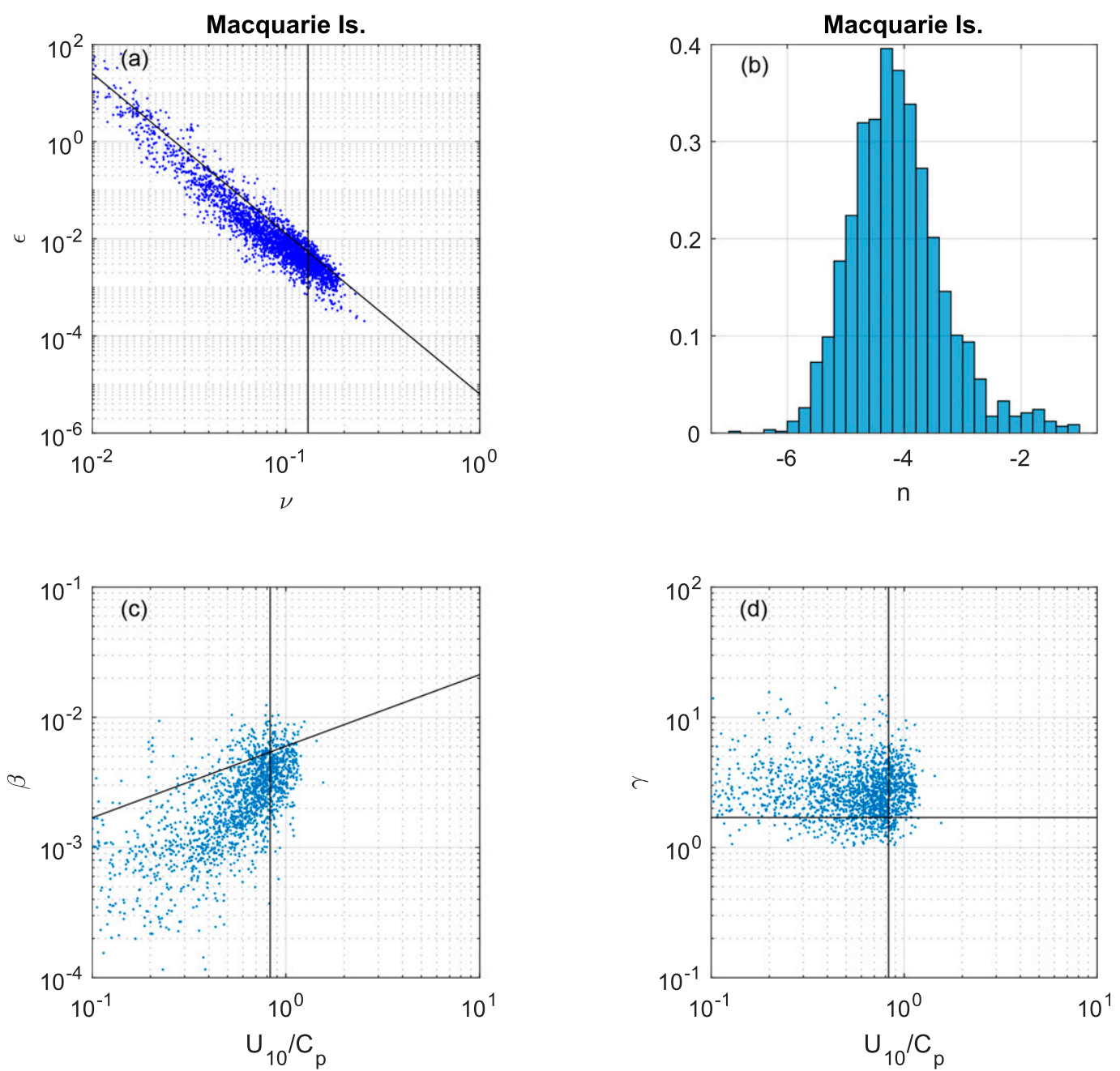

FIG. 8. As in Fig. 7, but recorded at Macquarie Island.

Following Longuet-Higgins et al. (1963), we have parameterized the direction spreading function as

$$
D(f, \theta)=\cos ^{2 s(f)}\left[\frac{\theta-\bar{\theta}(f)}{2}\right],
$$

where $s(f)$ defines the spreading width and $\bar{\theta}(f)$ is the mean direction. Note that the form defined by Eq. (8) explicitly excludes bimodal directional spreading. However, because this is only an issue at high frequencies, it is a reasonable simplification in the present context.

The data from all the buoys excluding OOI 2 were pooled and Eq. (8) was fitted to the spectra using a least squares approach. Figure 10 shows the median values of $s$ as a function of $f / f_{p}$, with the error bars shows \pm 1 standard deviation. Also shown in Fig. 10 is the parameterization proposed by Hasselmann et al. (1980) for fetchlimited wind waves. The form shown in Fig. 10 is $s\left(f / f_{p}\right)=9.77\left(f / f_{p}\right)^{-2.08}$, which was determined assuming a representative value of $U_{10} / C_{p}=1$. Although the present data are generally for $U_{10} / C_{p}<1$, because the Hasselmann et al. (1980) form does not extend to such values, this limit was chosen as a representative case for full development. The Hasselmann et al. (1980) form is in remarkably good agreement with the present Southern Ocean data, despite the fact that the data presented here are for cases where the spectral energy balance is likely very different to that experienced in fetch-limited wind seas (see section 7).

\section{Active wave generation processes}

As noted in section 3b, the WAVEWATCH III model was run for the periods spanning the recorded data from each of the in situ buoy datasets (Table 1). The purpose of these runs was to use the model as a diagnostic tool to try and understand the physical processes active in generating the spectral forms reported in section 6 . 
(a) Campbell Is. 18/05/17 0000

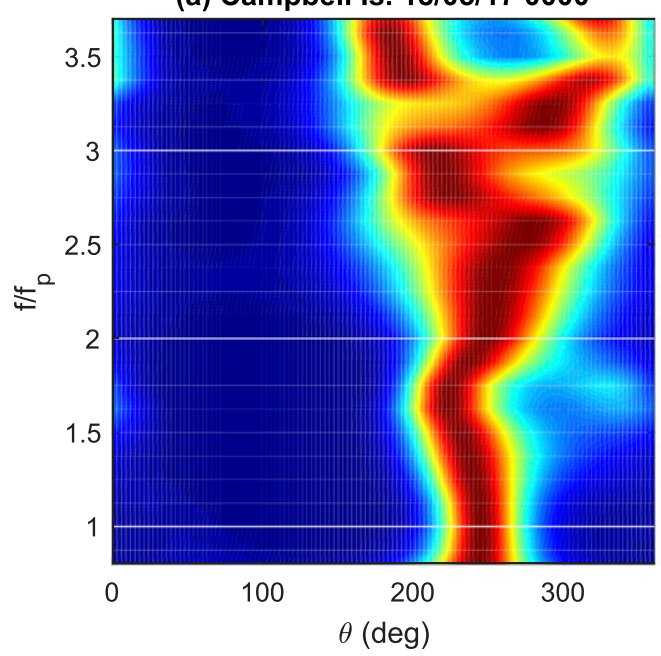

(b) Campbell Is. 18/05/17 0000

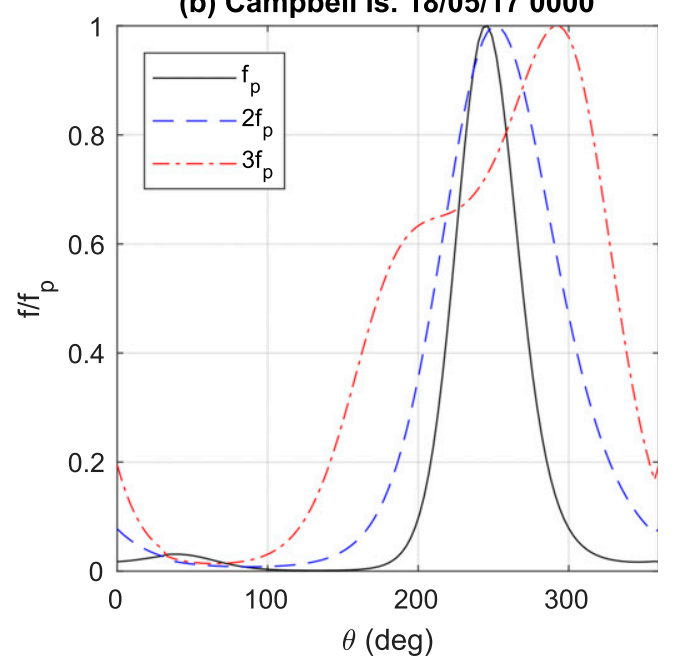

FIG. 9. Directional spectra recorded at Campbell Island at 0000 UTC 18 May 2017: (a) Shaded distribution of the directional spreading function $D(f, \theta)$ in Eq. (7). The horizontal white lines are drawn at $f_{p}, 2 f_{p}$, and $3 f_{p}$. (b) Directional slices through $D(f, \theta)$ at $f_{p}, 2 f_{p}$, and $3 f_{p}$.

Although such a model represents (in an operational context) present-day understanding of the physical processes active in wind wave evolution, there are still a number of approximations needed to make such a global model computationally efficient. The most significant of these is for the nonlinear term $S_{\mathrm{nl}}$, for which the discrete interaction approximation (The WAMDI Group 1988) that is used is a significant simplification. Therefore, to have confidence in using the model to interpret the physical processes that are active, it first needs to demonstrate that it can reproduce the observed data to reasonable accuracy. That is, that the model physics produces results consistent with observations.

Figure 11 shows the Southern Ocean region modeled at 0600 UTC 28 April 2012. The figure shows color shaded values of $H_{s}$ and vectors of mean wave direction. The time shown corresponds to the large wave case at the SOFS buoy reported in section $5 \mathrm{~b}$ and Fig. 5 . The storm south of Tasmania that produced these extreme conditions is clear in this figure. More generally, the figure shows a typical case for the Southern Ocean with a series of low pressure systems (storms) propagating clockwise (from west to east) around Antarctica. The mean wave direction south of $40^{\circ} \mathrm{S}$ is generally from the west to southwest. At lower latitudes, the wave direction turns more to the north as swell from the Southern Ocean propagates into the Indian, Pacific, and South Atlantic Oceans.

Figure 12 shows comparisons of $H_{s}$ between the model and in situ buoys for both the SOFS and OOI1 locations. The figure shows time series of $H_{s}$ spanning the periods during which the largest significant wave heights were recorded at each location (section 5b; Figs. 12a,b), as well as scatterplots for $H_{s}$ for the full periods of the buoy data (Figs. 12c,d). These results show that the model generally reproduces the observed $H_{s}$ reasonably well. The results are particularly impressive when it is noted that no attempt has been made to calibrate the model or the CFSR winds used to force the model. It is clear in Figs. $12 \mathrm{a}$ and $12 \mathrm{~b}$ that the model does consistently underestimate $H_{s}$ at the peaks of large storms, presumably due to underestimation of the CFSR wind speeds or limitations in the model physics. In general, however, the model performance is such that we conclude that the

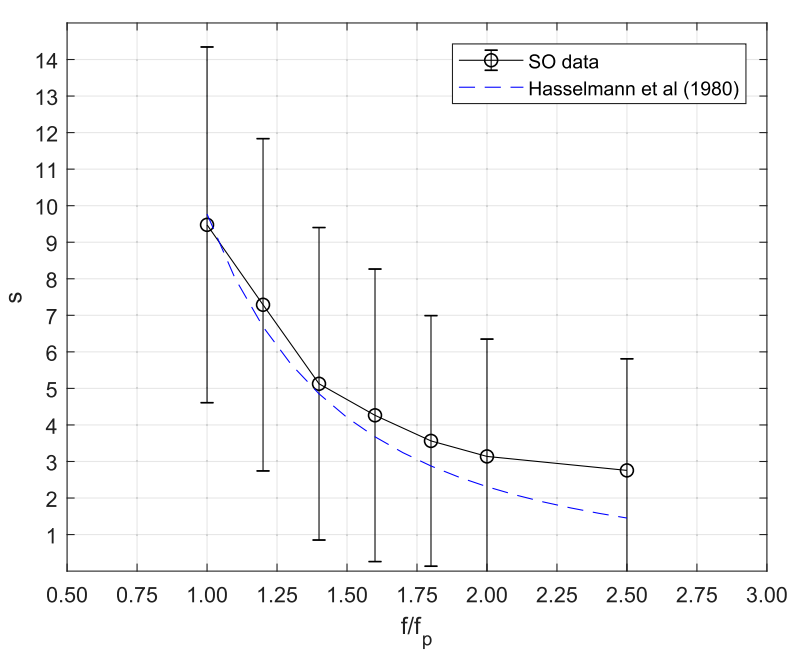

FIG. 10. The directional spreading exponent, $s$ in Eq. (8) as a function of $f / f_{p}$. The solid black line with vertical bars shows the median and \pm 1 std dev of buoy data from all stations. The dashed blue line is the fetch-limited result of Hasselmann et al. (1980). 


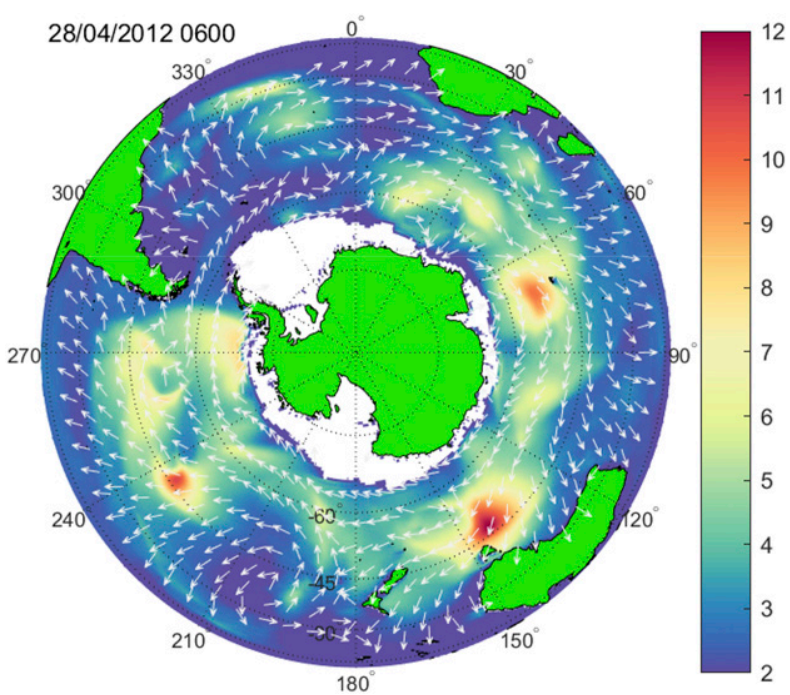

FIG. 11. Color-shaded values of $H_{s}(\mathrm{~m})$ from the WAVEWATCH III model at 0600 UTC 28 Apr 2012. The white arrows are the mean wave directions.

physics used in the model reproduces the major features of the observed conditions.

Figure 13 shows the source terms produced by the WAVEWATCH III model at the SOFS site at 0600 UTC 15 April 2012. This is a period shown in Fig. 12a but earlier than the time of peak conditions reported above. We have deliberately not used the case for the extreme storm since, as reported above, the model does not reproduce such extreme conditions well. The time shown in Fig. 13 is representative of typical conditions, with $H_{s} \approx 4 \mathrm{~m}$. The figure shows that the model and buoy 1D spectra are in reasonable agreement. The spectral level predicted by the model for higher frequencies is a little higher than the buoy data; however, both model and buoy data indicate a spectrum that is approximately proportional to $f^{-4}$. The model and buoy data are also in reasonable agreement as to the value of the spectral peak frequency, $f_{p}$, with the model producing a slightly lower value.

As shown in Fig. 13, the source-term balance at higher frequencies is such that $S_{\text {tot }} \approx S_{\text {in }}+S_{\mathrm{nl}}+S_{\mathrm{wc}} \approx 0$. That is, the high-frequency face of the spectrum is in equilibrium and is not growing/decaying, and the spectral balance is consistent with observations for fetch-limited wind seas. In the region near the spectral peak, the source term balance is very different. Because $U_{10} / C<0.83$ in these regions, $S_{\text {in }} \approx 0$. The white-cap dissipation is also such that $S_{\mathrm{wc}} \approx 0$, presumably because the wave slope is small for these waves. There is a small amount of swell dissipation (negative values of $S_{\mathrm{swl}}$ ) near the spectral peak. By far, the largest-magnitude source term in the spectral peak region is the nonlinear term $S_{\mathrm{nl}}$, where there is a transfer of energy from frequencies above the spectral peak to the spectral peak region. Therefore, the balance at the spectral peak becomes $S_{\text {tot }} \approx S_{\mathrm{nl}}+S_{\mathrm{swl}}$, which is positive, resulting in a continued growth of components near the spectral peak despite the fact that there is no active wind input.

The source terms reproduced in Fig. 13 do not show the advection of wave energy to the location that, in the Southern Ocean, will be significant as demonstrated by the generally west-to-southwest mean wave direction (Fig. 11), irrespective of the local wind directions, which will rotate around the low pressure systems in clockwise directions (Southern Hemisphere). Noting this, our interpretation of the full energy balance is as follows.

At any given point, the following hold:

- Significant energy will be advected to the site from the west.

- Because there are consistent winds across large areas of the Southern Ocean and a progression of low pressure systems, this energy advected to the site will not take the form of tradition narrow-banded swell. Rather, it will either consist of a spread of swell trains at different frequencies or a relatively broad frequency band of wave energy. That is, the energy is not arriving at the site from a single distant storm but from a progression of storms and sustained high winds over a very large region to the west of the location.

- As noted by Young and van Vledder (1993), one of the characteristics of the nonlinear terms is its "shape stabilizing" impact, which continually shapes the spectrum to a unimodal shape. In this case, this continual advection of westerly wave energy is combined with the local wind sea and shaped into the unimodal form seen in the buoy data and reproduced by WAVEWATCH III.

It is interesting to note that, in addition to reproducing observed values of $H_{s}$, WAVEWATCH III is also capable of reproducing the unimodal spectral shape. This means that, despite the limitations of the Discrete Interaction Approximation representation of the nonlinear source term, it is still capable of reproducing the shape-stabilizing character of this term.

As noted above and in Fig. 10, the directional spread is very similar to fetch-limited wind seas, even at the spectral peak, where there is no input or white-cap dissipation. This suggests that it is $S_{\mathrm{nl}}$ that primarily controls the directional spreading, since in the present case a spectral balance at the peak defined by $S_{\mathrm{nl}}+S_{\mathrm{swl}}$ produces approximately the same spreading as a fetch-limited wind sea where the spectral balance is $S_{\mathrm{in}}+S_{\mathrm{nl}}+S_{\mathrm{wc}}$.

As noted above, the situation at OOI2 appears to be very different from the other sites in that the 1D spectra are more often bimodal at this site. Because this location 

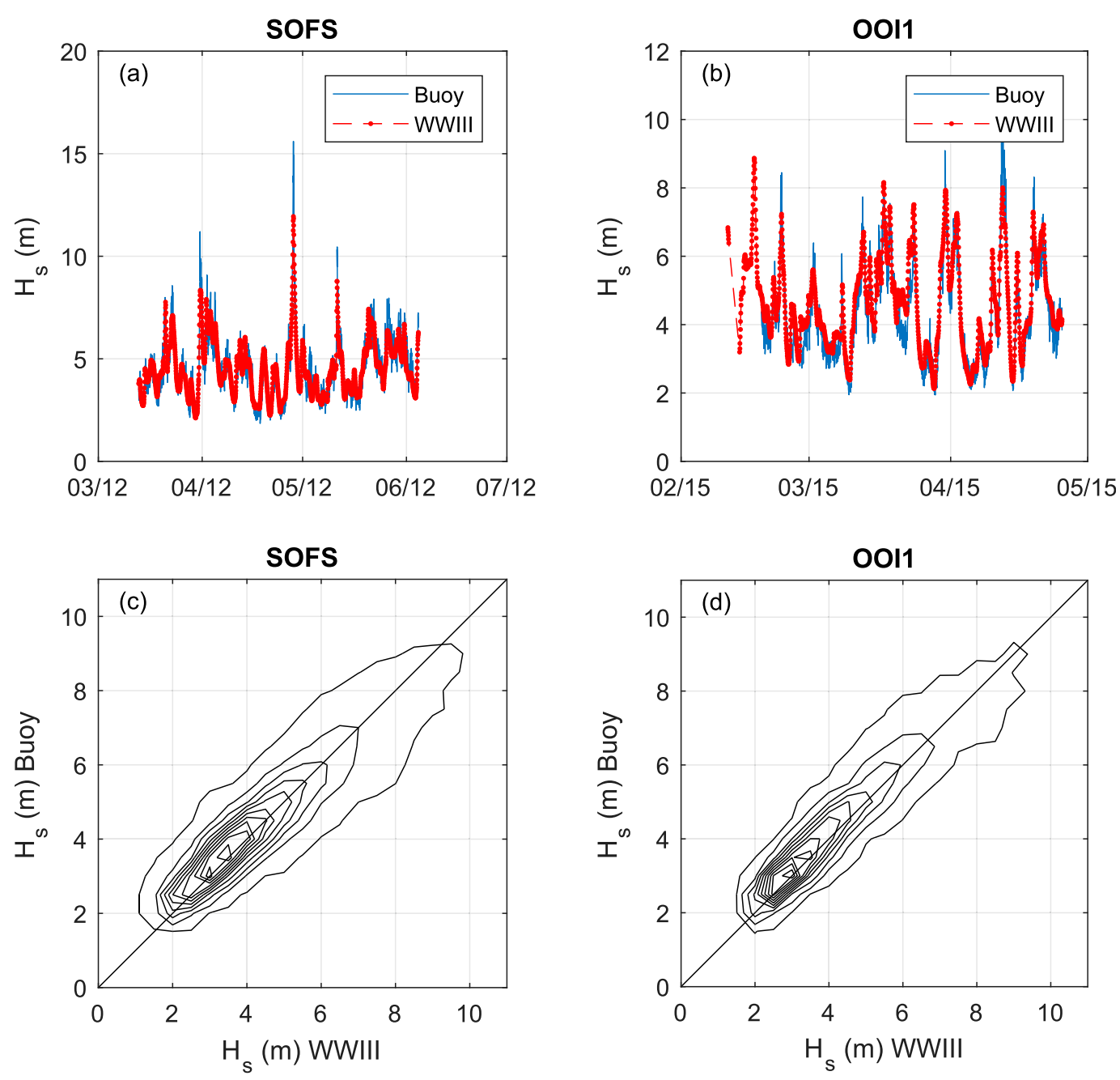

FIG. 12. Comparisons between buoy and WAVEWATCH III values of $H_{s}$ : (a),(b) Time series of $H_{s}$ and (c),(d) density contour scatterplots of buoy vs WAVEWATCH III values of $H_{s}$ at the (left) SOFS buoy during 2012 and (right) OOI1 buoy during 2015. Contours in (c) and (d) are drawn at 0.01, 0.1, 0.2, ., 0.9.

is in the wave shadow east of South America (Fig. 3), the wave climate at this location is very different. As is clear in the model output in Fig. 11, the mean wave direction at this location is from the south, rather than the west as at other locations in the Southern Ocean. This occurs because the westerly propagation of energy is largely blocked by South America. Energy that does arrive at this site consists of swell that has passed through Drake Passage and propagated north on a Great Circle. The spectrum at this location will then consist of wind sea associated with local winds, together with this southerly swell. These two systems act as a more conventional decoupled wind-sea-swell combination. These systems are separated significantly in both frequency and direction space and hence there is little coupling between them by $S_{\mathrm{nl}}$. As such, the spectra are more commonly bimodal in frequency space.
As noted above, the Southern Ocean is unique in that it has extremely long, unbroken fetches and an almost continual feed of swell energy from a progression of upwind storm systems. This situation then results in the unimodal 1D spectra with very low peak frequencies reported above. These types of spectral forms have, however, been observed in other "swell dominated" seas. Data from some areas of tropical cyclones (Young 1998a, 2006) show similar spectral forms. In this case, the spectra are directionally skewed, with a lowfrequency swell system generated in the intense wind regions near the center of the storm and a local wind sea. Despite the directional skewing, the 1D spectra $E(f)$ remain unimodal. Amurol and Ewans (2019) have also reported wave spectra measured off the cost of Malaysia where there is clearly remotely generated swell present but $1 \mathrm{D}$ spectra that are unimodal. These 

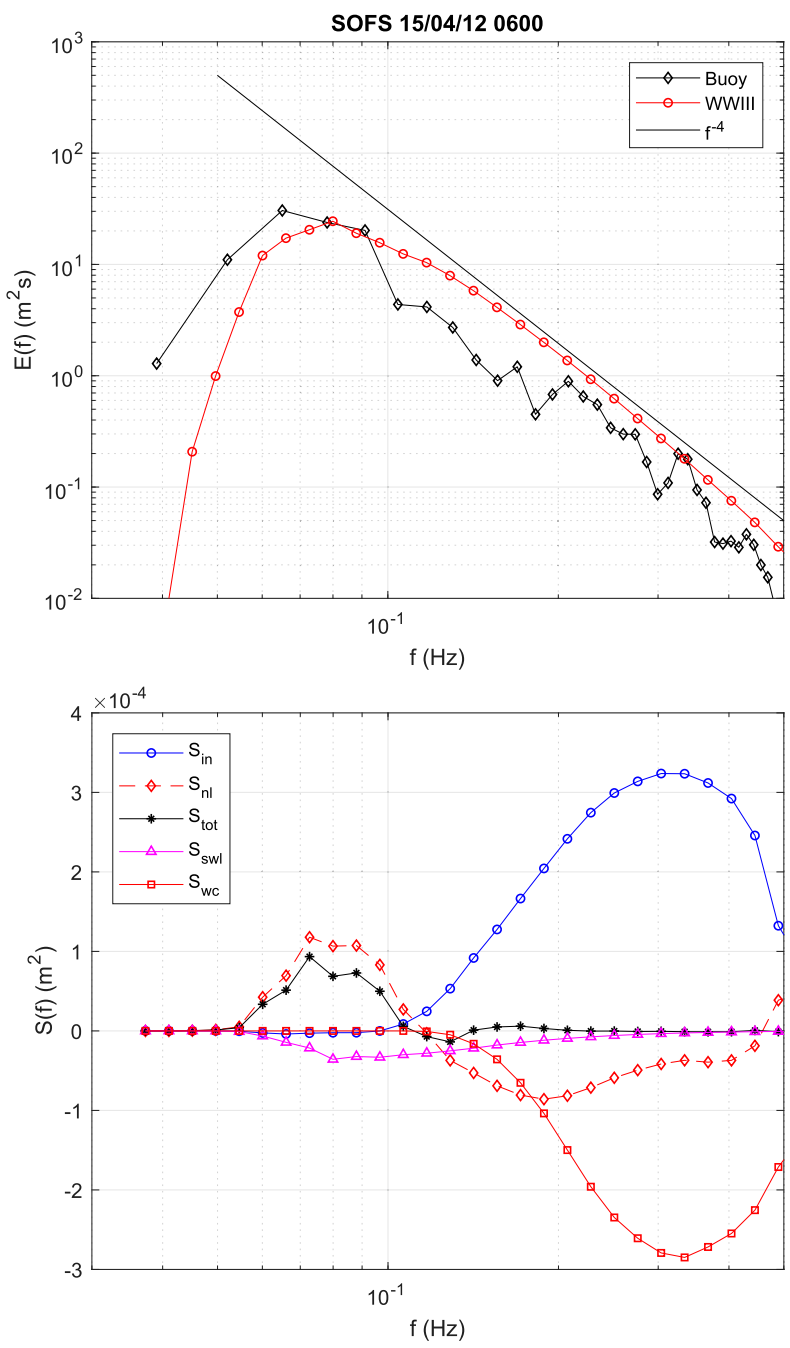

FIG. 13. Comparison of buoy and model spectra and source terms at the SOFS buoy: (top) 1D spectra from SOFS buoy and WAVEWATCH III model at 0600 UTC 15 Apr 2012 and (bottom) 1D source terms from SOFS buoy and WAVEWATCH III model at 0600 UTC 15 Apr 2012.

cases, together with the present data, demonstrate that a spectral balance near the spectral peak where the only significant source term is nonlinear interaction can result in these spectral forms.

Throughout this paper, we comment on the long, almost infinite fetches that exist in the Southern Ocean. The concept of an "infinite" fetch is clearly a simplification of the real situation. Because the Earth is not flat, wave energy generated by the prevailing westerly winds will continually "leak out" to the north along great circle paths. This is why Southern Ocean swell is ubiquitous across so many oceanic basins. In effect, the "fetch" in the Southern Ocean is continually rotating because of the curvature of the Earth. This rate of change of direction is, however, very slow relative to the time scales of meteorological systems, and the westerly winds will also act to generate new energy and partially steer the mean wave direction back to the south. As a result, the infinite-fetch concept is a reasonable descriptive approximation.

\section{Conclusions}

This analysis combines data from satellite altimeter observations, in situ buoy measurements, and spectral wave modeling to investigate the wave climate of the Southern Ocean. This analysis shows that the Southern Ocean has a relatively unique spatial wave climate generated by the strong westerly winds that prevail in the region, together with the very long uninterrupted fetch that exists. This configuration results in a wave climate in which the distribution of significant wave height is remarkably uniform across large areas of ocean, with mean wave energy propagating from west to east. The only significant area of land to impinge on the region is provided by Drake Passage, which results in a significant reduction in wave energy east of the passage.

The 1D wave spectra are generally unimodal but with spectral peak frequencies that are typically less than $0.07 \mathrm{~Hz}$. At such frequencies, there is typically no wind forcing near the peak of the spectrum. As a result, the spectral balance near the spectral peak is largely governed by nonlinear interactions. These nonlinear interactions, together with the continual feed of remotely generated waves coming from the multiple storms to the west, generate the observed unimodal spectra. It is believed that no other geographic location generates wave spectra of this form.

Acknowledgments. Author Young acknowledges the support of the Integrated Marine Observing System (IMOS). Authos Liu and Babanin acknowledge support from the DISI Australia-China Centre through grant ACSRF48199.

\section{REFERENCES}

Alves, J.-H. G. M., 2006: Numerical modeling of ocean swell contributions to the global wind-wave climate. Ocean Modell., 11, 98-122, https://doi.org/10.1016/j.ocemod.2004.11.007.

Amurol, S., and K. Ewans, 2019: The effect of swell on wave spectra of extreme sea states offshore Sarawak, Malaysia. Ocean Eng., 189, 106288, https://doi.org/10.1016/j.oceaneng.2019.106288.

Barbariol, F., A. Benetazzoa, L. Bertottia, L. Cavaleria, T. Durrantb, P. McComb, and M. Sclavoa, 2019: Large waves and drifting buoys in the Southern Ocean. Ocean Eng., 172, 817-828, https:// doi.org/10.1016/j.oceaneng.2018.12.011.

Caires, S., and A. Sterl, 2005: 100-year return value estimates for ocean wind speed and significant wave height from the 
ERA-40 data. J. Climate, 18, 1032-1048, https://doi.org/ 10.1175/JCLI-3312.1.

Coles, S., 2001: An Introduction to Statistical Modelling of Extreme Value Theory. Springer, 208 pp.

Donelan, M., M. Hamilton, and W. Hui, 1985: Directional spectra of wind-generated ocean waves. Philos. Trans. Roy. Soc., A315, 509-562, https://doi.org/10.1098/RSTA.1985.0054.

Ewans, K. C., 1998: Observations of the directional spectrum of fetchlimited waves. J. Phys. Oceanogr., 28, 495-512, https://doi.org/ 10.1175/1520-0485(1998)028<0495:OOTDSO > 2.0.CO;2.

Hasselmann, D. E., M. Dunckel, and J. A. Ewing, 1980: Directional wave spectra observed during JONSWAP 1973. J. Phys. Oceanogr., 10, 1264-1280, https://doi.org/10.1175/15200485(1980)010<1264:DWSODJ > 2.0.CO;2.

Hemer, M., 2010: Historical trends in Southern Ocean storminess: Long-term variability of extreme wave heights at Cape Sorell, Tasmania. Geophys. Res. Lett., 37, L18601, https://doi.org/ 10.1029/2010GL044595.

Isobe, M., K. Kondo, and K. Horikawa, 1984: Extension of MLM for estimating directional wave spectrum. Introduction to Coastal Engineering and Management: Proceedings of Symposium on Description and Modelling of Directional Seas, J. W. Kamphuis, Ed., Danmarks Tekniske Hojskole, $1-15$.

Josberger, E. G., and N. M. Mognard, 1996: Southern Ocean monthly wave fields for austral winters $1985-1988$ by Geosat radar altimeter. J. Geophys. Res., 101, 6689-6696, https:// doi.org/10.1029/95JC02963.

Krogstad, H. E., A. K. Magnusson, and M. A. Donelan, 2006: Wavelet and local directional analysis of ocean waves. Int. J. Offshore Polar Eng., 16, 97-103.

Liu, Q., W. E. Rogers, A. V. Babanin, I. R. Young, L. Romero, S. Zieger, and F. Qiao, 2019: Observation-based source terms in the third-generation wave model WAVEWATCH III: Updates and verification. J. Phys. Oceanogr., 49, 489-517, https://doi.org/10.1175/JPO-D-18-0137.1.

Longuet-Higgins, M. S., D. E. Cartwright, and N. D. Smith, 1963: Observations of the directional spectrum of sea waves using the motion of a floating buoy. Ocean Wave Spectra, Prentice Hall, 111-136.

Lygre, A., and H. E. Krogstad, 1986: Maximum entropy estimation of the directional distribution in ocean wave spectra. J. Phys. Oceanogr., 16, 2052-2060, https://doi.org/10.1175/ 1520-0485(1986)016<2052:MEEOTD > 2.0.CO;2.

MacIsaac, C., and S. Naeth, 2013: TRIAXYS Next Wave II Directional Wave Sensor: The evolution of wave measurements. 2013 OCEANS, San Diego, CA, IEEE, 1-8, https:// doi.org/10.23919/OCEANS.2013.6741003.

Meucci, A., I. R. Young, and $\varnothing$. Breivik, 2018: Wind and wave extremes from atmosphere and wave model ensembles. J. Climate, 31, 8819-8842, https://doi.org/10.1175/JCLI-D-18-0217.1.

,,-- O. J. Aarnes, and O. Breivik, 2020: Comparison of wind speed and wave height trends from twentieth century models and satellite altimeters. J. Climate, 33, 611-624, https://doi.org/ 10.1175/JCLI-D-19-0540.1.

Mognard, N. M., W. J. Campbell, R. E. Cheney, and J. G. Marsh, 1983: Southern Ocean mean monthly waves and surface winds for winter 1978 by SEASAT radar altimeter. J. Geophys. Res., 88, 1736-1744, https://doi.org/10.1029/JC088iC03p01736.

,,,,---- and D. Ross, 1986: Southern Ocean waves and winds derived from SEASAT altimeter measurements. Wave Dynamics \& Radio Probing of the Sea Surface, O. M. Phillips and K. Hasselmann, Eds., Plenum, 479-489.
Morim, J., and Coauthors, 2019: Robustness and uncertainties in global multivariate windwave climate projections. Nat. Climate Change, 9, 711-718, https://doi.org/10.1038/s41558019-0542-5.

Rapizo, H., A. V. Babanin, E. Schulz, M. A. Hemer, and T. H. Durrant, 2015: Observation of wind-waves from a moored buoy in the Southern Ocean. Ocean Dyn., 65, 1275-1288, https://doi.org/ 10.1007/s10236-015-0873-3.

_, T. H. Durrant, and A. V. Babanin, 2018: An assessment of the impact of surface currents on wave modeling in the Southern Ocean. Ocean Dyn., 68, 939-955, https://doi.org/ 10.1007/s10236-018-1171-7.

Ribal, A., and I. R. Young, 2019: 33 years of globally calibrated wave height and wind speed data based on altimeter observations. Sci. Data, 6, 77, https://doi.org/10.1038/s41597-0190083-9.

Rogers, W. E., A. V. Babanin, and D. W. Wang, 2012: Observation consistent input and whitecapping dissipation in a model for wind-generated surface waves: Description and simple calculations. J. Atmos. Oceanic Technol., 29, 1329-1346, https:// doi.org/10.1175/JTECH-D-11-00092.1.

Saha, S., and Coauthors, 2010: The NCEP Climate Forecast System Reanalysis. Bull. Amer. Meteor. Soc., 91, 1015-1057, https:// doi.org/10.1175/2010BAMS3001.1.

_ , and Coauthors, 2014: The NCEP Climate Forecast System version 2. J. Climate, 27, 2185-2208, https://doi.org/10.1175/ JCLI-D-12-00823.1.

Schulz, E., M. A. Grosenbaugh, L. Pender, D. J. M. Greenslade, and T. W. Trull, 2011: Mooring design using wave-state estimate from the Southern Ocean. J. Atmos. Oceanic Technol., 28, 1351-1360, https://doi.org/10.1175/JTECHD-10-05033.1.

_ , S. A. Josey, and R. Verein, 2012: First air-sea flux mooring measurements in the Southern Ocean. Geophys. Res. Lett., 39, L16606, https://doi.org/10.1029/2012GL052290.

Semedo, A., K. Suselj, A. Rutgersson, and A. Sterl, 2011: A global view on the wind sea and swell climate and variability from ERA-40. J. Climate, 24, 1461-1479, https://doi.org/10.1175/ 2010JCLI3718.1.

Steedman, R. K., 1993: Data report on Southern Ocean surface wave climate adjacent Macquarie Island November 1988 to October 1989. Steedman Science \& Engineering. Rep. R594, 199 pp.

Takbash, A., and I. R. Young, 2019: Global ocean extreme wave heights from spatial ensemble data. J. Climate, 32, 6823-6836, https://doi.org/10.1175/JCLI-D-19-0255.1.

,$- \ldots$, and O. Breivik, 2019: Global wind speed and wave height extremes derived from long-duration satellite records. J. Climate, 32, 109-126, https://doi.org/10.1175/JCLI-D-18-0520.1.

The WAMDI Group, 1988: The WAM model-A third generation ocean wave prediction model. J. Phys. Oceanogr., 18 1775-1810, https://doi.org/10.1175/1520-0485(1988)018<1775: TWMTGO > 2.0.CO;2.

Tolman, H. L., 2003: Treatment of unresolved islands and ice in wind wave models. Ocean Modell., 5, 219-231, https://doi.org/ 10.1016/S1463-5003(02)00040-9.

WW3DG, 2016: User manual and system documentation of WAVEWATCH III version 5.16. NOAA/NWS/NCEP/MMAB Tech. Note 329, 326 pp., https://polar.ncep.noaa.gov/waves/ wavewatch/manual.v5.16.pdf.

Young, I. R., 1994a: Global ocean wave statistics obtained from satellite observations. Appl. Ocean Res., 16, 235-248, https:// doi.org/10.1016/0141-1187(94)90023-X. 
1994b: On the measurement of directional wave spectra. Appl. Ocean Res., 16, 283-294, https://doi.org/10.1016/ 0141-1187(94)90017-5.

_ 1998a: Observations of the spectra of hurricane generated waves. Ocean Eng., 25, 261-276, https://doi.org/10.1016/S00298018(97)00011-5.

— 1998b: An intercomparison of GEOSAT, TOPEX and ERS1 measurements of wind speed and wave height. Ocean Eng., 26, 67-81, https://doi.org/10.1016/S0029-8018(97)10016-6.

_ 1999: Seasonal variability of the global ocean wind and wave climate. Int. J. Climatol., 19, 931-950, https://doi.org/10.1002/ (SICI)1097-0088(199907)19:9<931::AID-JOC412>3.0.CO;2-O.

- 2006: Directional spectra of hurricane wind-waves. J. Geophys. Res., 111, C08020, https://doi.org/10.1029/2006JC003540.

_ _ and G. Ph. van Vledder, 1993: A review of the central role of nonlinear interactions in wind-wave evolution. Philos. Trans. Roy. Soc. London, A342, 505-524, https://doi.org/10.1098/ rsta.1993.0030.

— Climate. Pergamon Press, 241 pp.

_ , and L. A. Verhagen, 1996: The growth of fetch limited waves in water of finite depth. Part II: Spectral evolution. Coastal Eng., 29, 79-99, https://doi.org/10.1016/S0378-3839(96)00007-5.
— and M. A. Donelan, 2018: On the determination of global ocean wind and wave climate from satellite observations. Remote Sens. Environ., 215, 228-241, https://doi.org/10.1016/ j.rse.2018.06.006.

, and A. Ribal, 2019: Multi-platform evaluation of global trends in wind speed and wave height. Science, 364, 548-552, https://doi.org/10.1126/science.aav9527.

_ L. A. Aerhagen, and M. L. Banner, 1995: A note on the bimodal directional spreading of fetch-limited wind waves. J. Geophys. Res., 100, 773-778, https://doi.org/10.1029/ 94JC02218.

— S. Zieger, and A. V. Babanin, 2011: Global trends in wind speed and wave height. Science, 332, 451-455, https://doi.org/ 10.1126/science.1197219.

_- E. Sanina, and A. V. Babanin, 2017: Calibration and crossvalidation of a global wind and wave database of altimeter, radiometer and scatterometer measurements. J. Atmos. Oceanic Technol., 34, 1285-1306, https://doi.org/10.1175/ JTECH-D-16-0145.1.

Zieger, S., A. V. Babanin, W. E. Rogers, and I. R. Young, 2015: Observation-based source terms in the third-generation wave model WAVEWATCH. Ocean Modell., 96, 2-25, https:// doi.org/10.1016/j.ocemod.2015.07.014. 